\title{
Outbreak, Prevalence and Mortality of Severe Acute Respiratory Syndrome (SARS-CoV-2) Infections in Kerala- A Perspective Study
}

\author{
S. Krishnakumar ${ }^{1}$ (D), Aabha Benjamin ${ }^{2}$ (D) , G. Prakash Williams 3,* (D) \\ 1 Department of Biomedical Engineering, School of Bio and Chemical Engineering, Sathyabama Institute of Science and \\ Technology, Chennai, Tamilnadu, India- 600 119; drskrishnakumarphd@ gmail.com (S.K.); \\ 2 Department of Economics, University College, Thiruvananthapuram, Kerala. India-695034; aabhabenjamin@gmail.com \\ (A.B.); \\ 3 Post Graduate Department of Botany and Biotechnology, Bishop Moore College, Mavelikara, Kerala, India- 690110; \\ prakash.gw@gmail.com (G.P.W.); \\ * Correspondence: prakash.gw@gmail.com;
}

Scopus Author ID 37024554200

Received: 10.08.2020; Revised: 1.10.2020; Accepted: 2.10.2020; Published: 6.10.2020

\begin{abstract}
Severe acute respiratory syndrome (SARS-CoV-2) is the causative agent of infectious disease COVID-19. In India, since the first case reported in Kerala, on January 30, 2020, the outbreak has gradually spread nationwide. The epidemic effect of COVID-19 infection was carried out from January 30 to April 28, 2020 (90 days) across the state. Among the districts studied, Kasaragod and Kannur district exhibit the highest COVID-19 cases, whereas Alapuzha and Wyanad districts have the least number of positive cases. The new positive COVID-19 cases were reported exponentially after 45 days to 75 days. There was a decline in the number across the state. As of April 28, 2020, the number of positive cases was 485, recovered cases were 356 , active cases were 123 , and the fatal cases were 3 . Among gender, male individuals are more susceptible to COVID-19 infection than female individuals. The number of newly diagnosed patients has been declining, and the epidemic is gradually being controlled.
\end{abstract}

Keywords: coronavirus; SARS-CoV-2; COVID-19; pneumonia; mortality.

(C) 2020 by the authors. This article is an open-access article distributed under the terms and conditions of the Creative Commons Attribution (CC BY) license (https://creativecommons.org/licenses/by/4.0/).

\section{Introduction}

A novel virus causing severe acute respiratory syndrome (SARS-CoV-2) was identified as the causative agent of pneumonia cases, named coronavirus disease 2019 (COVID-19). It was initially perceived in Wuhan City, China, during December 2019. The disease had spread to more than 200 countries by April 2020 (WHO, 2020) [1]. The primary origin of SARS-CoV2 is a bat and transmitted to humans through an intermediate host, Pangolin. SARS-CoV-2 has $>95 \%$ homology with bat coronaviruses [2]. After Severe Acute Respiratory Syndrome (SARS) in 2003 [3] and the Middle East Respiratory Syndrome (MERS) in 2012 [4], SARSCoV-2 characterize the third coronavirus associated epidemic emerging from zoonotic to humans [5]. The phylogenetic data of coronavirus 2 implicate a zoonotic origin [6] but the rapid spread of infection from one person to another by direct or indirect means [7]. The occurrence of the COVID-19 epidemic follows a nonlinear process quite similar to the epidemic of SARS that occurred in Hong Kong in 2003 [8], the Ebola in West Africa during 2013 - 2016 [9], and the pandemic of H1N1 in 2009 [10]. Hence, vigorous efforts have been 
initiated by the state government to treat infected patients separately in state government hospitals.

In India, the first case of SARS-CoV-2 infection was reported in Kerala on January 30, 2020, through a medical student who traveled from China. Then the COVID 19 epidemic slowly increased from January 30, 2020, to March 15, 2020, across Kerala. Immediately, massive actions were taken for a national lockdown. It applied to all business sectors and educational institutions. This case report describes the outbreak, prevalence, and mortality of COVID-19 infection for 90 days in Kerala, India.

Coronavirus is an RNA virus with size ranging from 0.06 to 0.14 microns in diameter and spike-like protein projections on its surface, giving it a "crown" like appearance under an electron microscope. As per the phylogenetic analysis, the SARS-CoV-2 belongs to the SARS$\mathrm{CoV}$ strain. The evidence-based on genomic analysis suggests that SARS-CoV-2 shares with SARS-CoV. Both strains have the same human cell receptor angiotensin-converting enzyme 2 (ACE2) to enter host cells. The analysis of receptor affinity shows that the 2019 strain of SARS-CoV-2 is more efficient in binding with ACE2 than the 2003 strain [11]. ACE2 is an anchored surface protein present on the plasma membrane of cells of the lower respiratory tract [12]. The higher receptor affinity for ACE2 of SARS-CoV-2 may be responsible for its lung involvement in COVID-19 infection. In vitro inoculation of the strain of SARS-CoV2 on the human airway surface, epithelial cells cause cessation of the cilia movements and cytopathic effects [13].

\section{Materials and Methods}

The study is made on the outbreak, prevalence, and mortality rate of COVID-19 positive cases reported in Kerala between January 30 and April 28, 2020 (90 days). This study is based on the data obtained from the Directorate of Health Services (DHS), Government of Kerala, and various news outlets.

Researchers and investigators were not permitted to collect information directly from Covid-19 patients, health workers, or health care institutions. Information was collected from health workers through an informal interview. Data was secured from the 'Daily Bulletin' published by the Directorate of Health Services, Kerala, various newspapers, the website maintained by the Volunteers at CODD-K Team, supported by Government College, Kasaragod [14]. Information was also collected from health workers through an informal interview.

\section{Results and Discussion}

A respiratory disorder characterizes COVID-19 with a varying degree of severity, varied from a mild upper respiratory tract illness to acute respiratory distress syndrome (ARDS) [15]. Estimates of the case fatality ratio might vary slightly from country to country due to differences in prevention and control measures implemented by the government and health care departments.

\subsection{District wise prevalence of COVID-19.}

Kerala is the southernmost state of India, located in the Indian peninsula between the Lakshadweep Sea in the west, the Indian Ocean in the south, Tamil Nadu on the eastern side Karnataka in the north side, spread over $38,863 \mathrm{~km}^{2}$. Kerala's total population is 33.4 million, 
and the density of the population is 860 , with a total area of $130,058 \mathrm{sq} \mathrm{km}$. In India, the first COVID-19 epidemic was identified in Kerala from Thrissur district on January 30, 2020, through a medical student who traveled from China. Table 1 portrays the district wise report of Covid-19 positive cases in Kerala from January 30 to April 28, 2020 (90 days).

Table 1. Epidemic effect of COVID-19 positive cases in Kerala during the study period.

\begin{tabular}{|c|c|c|c|c|c|c|c|}
\hline \multirow[b]{2}{*}{ S.No. } & \multirow[b]{2}{*}{ Districts } & \multicolumn{6}{|c|}{ No of positive cases } \\
\hline & & 15 days & 30 days & 45 days & 60 days & 75 days & 90 days \\
\hline 1 & Kasargode & 1 & 1 & 0 & 90 & 166 & 176 \\
\hline 2 & Kannur & 0 & 0 & 1 & 32 & 73 & 114 \\
\hline 3 & Idukki & 0 & 0 & 0 & 3 & 10 & 24 \\
\hline 4 & Ernakulam & 0 & 0 & 3 & 20 & 24 & 24 \\
\hline 5 & Kozhikode & 0 & 0 & 0 & 6 & 13 & 24 \\
\hline 6 & Malappuram & 0 & 0 & 0 & 10 & 20 & 23 \\
\hline 7 & Kottayam & 0 & 0 & 2 & 3 & 3 & 20 \\
\hline 8 & Pathanamthitta & 0 & 0 & 9 & 12 & 17 & 17 \\
\hline 9 & Thiruvananthapuram & 0 & 0 & 3 & 8 & 14 & 15 \\
\hline 10 & Kollam & 0 & 0 & 0 & 2 & 9 & 14 \\
\hline 11 & Thrissur & 1 & 1 & 2 & 7 & 13 & 13 \\
\hline 12 & Palakkad & 0 & 0 & 0 & 5 & 8 & 13 \\
\hline 13 & Alapuzha & 1 & 1 & 1 & 2 & 5 & 5 \\
\hline 14 & Wyanad & 0 & 0 & 0 & 1 & 3 & 3 \\
\hline Total & & 3 & 3 & 21 & 201 & 378 & 485 \\
\hline
\end{tabular}

Among the districts studied, Kasargode and Kannur district exhibit the highest COVID19 cases of 176 and 114, respectively, whereas Alapuzha and Wyanad district has reported the least number of positive cases during the study period. The state has reported 485 COVID 19 positive cases for 90 days due to travel history like return migrants from other states and other countries, intrafamily transmission, etc. Figure 1 displays district wise comparison of positive cases for 90days. Two districts, namely Kasargode and Kannur, remain the maximum number of positive reported from 60 days onwards. The other districts have recorded a comparatively lesser number of cases throughout the study period.

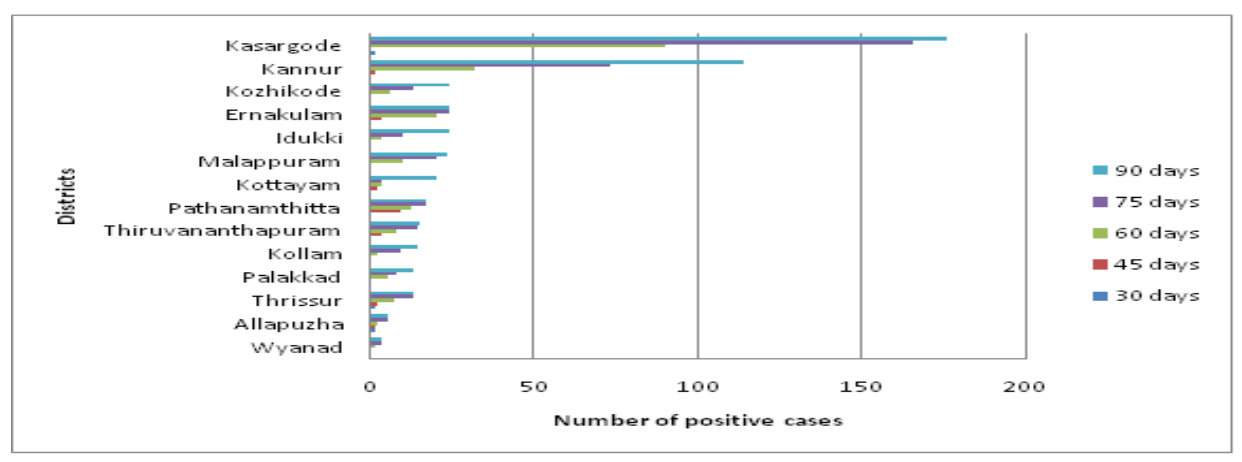

Figure 1. District-wise report of COVID-19 positive cases for 90days.

The number of infected cases increased rapidly in the state. Fig. 2 explains the trends of COVID-19 positive cases reported in Kerala between January 30 and April 28, 2020. Initially, the epidemic effect of disease spread was significantly less. The cases reported are generally the people who have had travel history from foreign countries and other states. After 45 days, there is a local transmission of the disease from the infected people to their families and those who contact them. Therefore, there is a steady rise in the cases reported, as seen in the chart from 45 days to 60 days. After that, an exponential hike in the number of positive cases was reported. The infection became extremely contagious from 60 days to 90 days. 


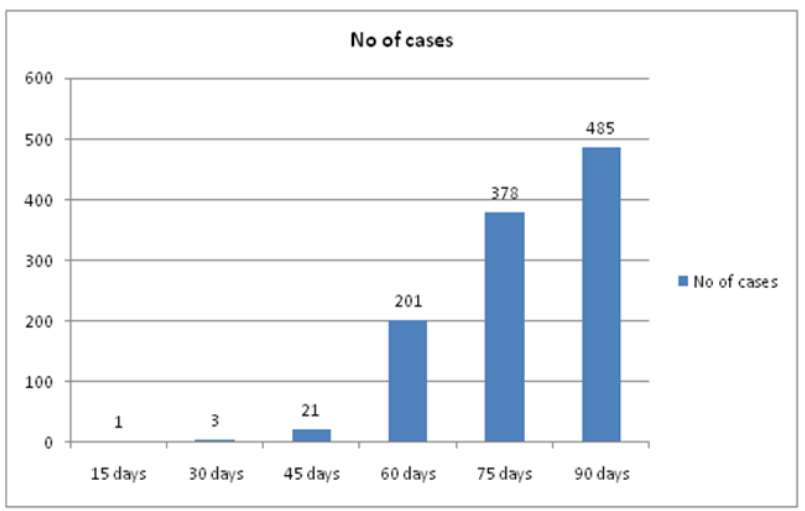

Figure 2. Prevalence of positive COVID -19 cases reported in Kerala during the study period.

The overall percentage increase/decrease of COVID-19 positive cases of the state during the study period is displayed in Fig. 3. The maximum percentage of disease incidence was observed during 45 days to 60 days due to intra family transmission and local transmission. During this period, the incidence of disease was 857 percent more than 30 days due to social and other contact. There is a gradual decline in disease occurrence after 60 days - 88 percent during 61 to 75 days and 28 percent from 76 days to 90 days. The infected individuals were isolated and social distance was maintained. The number of new positive COVID -19 cases reported in Kerala during the study period is presented in Fig. 4. Initially, for 15 days, only 3 cases were reported due to travel history from abroad and other states. However, between 16 to 30 days, not even a single new positive case was recorded. After 45 days, exponential new cases (179 cases) were recorded daily. They remained steady until 75 days (177 cases) across the state due to the local transmission and community spread. After that, there is a gradual fall in the number of new cases observed until the end of the study period due to nationwide lockdown implemented by the community's central and state government and social distance.

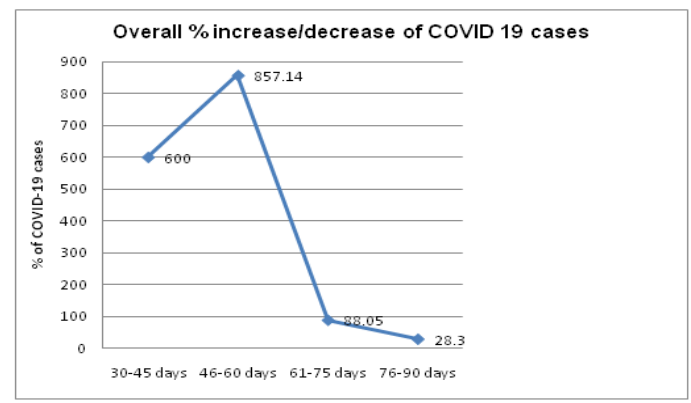

Figure 3. Overall percentage increase/decrease of COVID-19 cases during the study period.

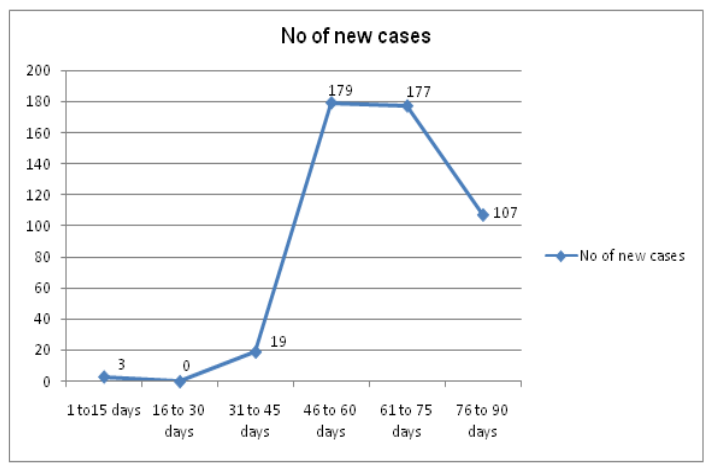

Figure 4. Number of new positive COVID -19 cases reported in Kerala during the study period. 
SARS-CoV-2 virus infects both gender and all age groups invariably across the world. Table 2 exhibits age and gender-wise distribution of positive cases in Kerala for 90 days. Among the age group studied, age between 21 and 40 has reported more vulnerable positive cases than the other age groups. The children between 1 and 10 have recorded less number of infected cases. At the same time, the older adults between 71 and 100 were less prone to SARS$\mathrm{CoV} 2$ infection during the state's study period. Among gender, males (297 cases) were more susceptible than female individuals (111 cases) on April 28, 2020. Huang et al. [16] reported that SARS-CoV-2 seems to prefer the elderly male population and patients with other health complications. SARS-CoV-2 is thought to be transmitted via contaminated hands, surfaces, aerosol droplets, and extensive human to human transmission and gathering of infected families and medical professionals [17].

Table 2. Age and gender-wise distribution of COVID-19 cases in Kerala for 90 days.

\begin{tabular}{|c|c|c|c|c|c|}
\hline \multirow[t]{2}{*}{ S.No } & \multirow[t]{2}{*}{ Age group } & \multicolumn{2}{|c|}{ Gender } & \multirow[t]{2}{*}{ Total } & \multirow{2}{*}{$\begin{array}{l}\text { Unspecified } \\
\text { cases* }\end{array}$} \\
\hline & & Male & Female & & \\
\hline 1 & $1-10$ & 8 & 7 & 15 & \multirow{11}{*}{77} \\
\hline 2 & $11-20$ & 19 & 17 & 36 & \\
\hline 3 & $21-30$ & 72 & 27 & 99 & \\
\hline 4 & $31-40$ & 90 & 17 & 107 & \\
\hline 5 & $41-50$ & 55 & 11 & 66 & \\
\hline 6 & $51-60$ & 36 & 16 & 52 & \\
\hline 7 & $61-70$ & 12 & 11 & 23 & \\
\hline 8 & $71-80$ & 1 & 2 & 3 & \\
\hline 9 & $81-90$ & 3 & 3 & 6 & \\
\hline 10 & $91-100$ & 1 & 0 & 1 & \\
\hline \multicolumn{2}{|c|}{ Total } & 297 & 111 & 408 & \\
\hline \multicolumn{4}{|c|}{ Grand total } & 485 & \\
\hline
\end{tabular}

(Source:https://covid19kerala.info/ retrieved on 29-04-2020; [14]

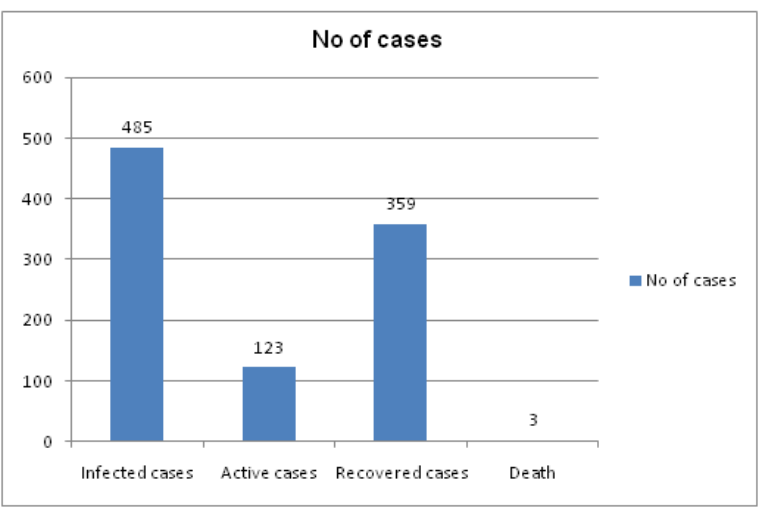

Figure 5. Outbreak and mortality rate of COVID-19 cases reported for 90 days in Kerala.

The epidemic effect of SARS-CoV2 infection worldwide is actively spreading, which could be potentially controlled only by hygienic practice and social distancing. Generally, there are no specific antiviral drugs to treat COVID-19 infected patients at present. Although most patients have mild symptoms after infection, some patients have developed a severe infection and are fatal due to other complications. Fig. 5 exhibits the infected, active, and recovered rate of COVID-19 cases reported for 90 days in Kerala. As of April 28, 2020, the number of positive cases reported during the study period is 485 . Among the infected patients, 359 cases were recovered entirely and discharged from the hospital. The remaining 123 active cases were under treatment in various state hospitals, whereas 3 cases died due to severe respiratory failure during the study period. The recovered rate of COVID-19 cases is $74 \%$. 
The mortality rate is $0.62 \%$ of infected cases during the study period in Kerala. The state's mortality rate is significantly less compared to the national fatal rate of 3 percent and a global fatal rate of 5 percent. The fatality ratio is significantly indebted to the attentiveness and availability of health care facilities of the state. Asymptomatic cases of SARS-CoV2 infection may result in the spread of the disease despite the government's measures. As depicted by the analysis of the epidemic curves provided by the study, the decreasing trend of infection may indicate the effectiveness of the control measure implemented to date [18]. Monica Gandhi et al. [19] reported that asymptomatic persons play a vital role in the spread of SARS-CoV-2.

To overcome the current crises, health care professionals and primary health care officials locate the infected area and quarantine those who have had contact with COVID 19 infected patients. The affected patients and their contacts were advised to regularly promote washing their hands with soap, use masks, and maintain social distance to prevent further infection.

\subsection{Kerala Model.}

Severe and strict lockdowns and triple lockdowns, were announced in areas were community spread was doubted or expected. Lockdown was announced in Kerala before the national one; schools were shut, gatherings were banned, a stricter, and more extended quarantine than the national norm was deployed [20]. The government adopted an iron-fist approach in implementing the lockdowns. Strict measures were taken against those who violated the guidelines of the authorities. The high educational status of Keralites made the government's task to convince them about the importance of social distancing easy. The "break the chain" campaign, which was launched to motivate people to clean their hands using soap and sanitizer to limit the Covid-19 spread, was successful [21].

The state government's socially valuable outreach policy also helped limit the spread of the disease in the initial days. The assurance was given by the Chief Minister of Kerala that 'nobody will starve during lockdown' created confidence and peace in the people's mind, which equipped them psychologically to stay home. Efficient local self-government combined with a well-developed health care system enabled Kerala's state to deal with the pandemic in a better way than other states and countries during the first 90 days. Necessary supplies for those who were in quarantine were home-delivered by local self-government. Mid-day meals from schools were sent to children even when schools were shut. Migrant laborers were treated as 'respectable guests' of the state and were well-taken care. Mental health helplines were opened across the state. The police distributed free food packets, and the government recognized volunteers to the destitute. Medicines were delivered to patients with a severe illness like cancer, kidney problem, etc. by the fire force. Another notable action from the local selfgovernment side was the opening of community kitchens in every panchayat to feed the people in isolation [22].

By May 7, a large number of Keralites started returning from various countries as part of the 'Vande Bharat' repatriation program. The return of lakhs of Malayalees triggered the increase in the number of COVID cases in Kerala. The return of Keralites from other states in India also aggravated the situation. COVID positive cases are also increasing in the coastal belt of Kerala. The fishermen have close interaction with fishers belonging to nearby states, which led to the spread of COVID cases in the coastal areas. The high density of the population in the coastal areas, poor sanitation conditions, low level of education of the fishermen, etc., are 
making it difficult for the authorities to control the situation. At present, the graph of corona positive cases is going up despite the government's stringent measures.

\section{Conclusions}

SARS-CoV-2 affects different people in different ways. Most of the infected people develop mild to moderate symptoms. SARS-CoV-2 seems to be a different strain regarding its phylogenetic and pathogenetic features. SARS-CoV-2 has more clinical features, and it can more easily enter into the community spread. So rapid screening, disease diagnosis, social distancing, quarantine, and disease-specific treatment are necessary to prevent further community spread. In Kerala, the increase in new cases of Covid-19 showed an exponential growth from 45 days to 60 days. The rate of growth of positive cases exhibited a significant fall after 75 days. As per the government authorities, up to the $90^{\text {th }}$ day after the outbreak of Covid-19, $74 \%$ of the affected persons got cured. The mortality rate is $0.62 \%$ of infected cases during the study period in Kerala. The state's mortality rate is significantly less compared to the national fatal rate of 3 percent and global fatal rate of 5 percent.

\section{Funding}

This research received no external funding.

\section{Acknowledgments}

The authors are thankful to Sathyabama Institute of Science and Technology (SIST), Chennai, Tamil Nadu, India, University College, Thiruvananthapuram, and Bishop Moore College, Mavelikara, Kerala, India for the facilities provided for the study.

\section{Conflicts of Interest}

The authors declare no conflict of interest. The funders had no role in the study; in the collection, analyses, or interpretation of data; in the writing of the manuscript, or in the decision to publish the results.

\section{References}

1. World Health Organization. Infection prevention and control of epidemic- and pandemic-prone acute respiratory infections in health care. Geneva: World Health Organization. 2020.

2. Petrosillo, N.; Viceconte, G.; Ergonul, O.; Ippolito, G.; Petersen, E. COVID-19, SARS and MERS: are they closely related? Clinical Microbiology and Infection 2020, 26, 729-734, https://doi.org/10.1016/j.cmi.2020.03.026.

3. Hui, D.S.C.; Zumla, A. Severe Acute Respiratory Syndrome. Infect Dis Clin North Am 2019, 3, 869-89.

4. Azhar, E.I.; Hui, D.S.C.; Memish, Z.A.; Drosten, C.; Zumla, A. The Middle East Respiratory Syndrome (MERS). Infectious Disease Clinics 2019, 33, 891-905, https://doi.org/10.1016/j.idc.2019.08.001.

5. Viceconte, G.; Petrosillo, N. COVID-19 R0: Magic number or conundrum? Infect Dis Rep 2020, 12, 85168516, https://doi.org/10.4081/idr.2020.8516.

6. Lu, R.; Zhao, X.; Li, J.; Niu, P.; Yang, B.; Wu, H.; Wang, W.; Song, H.; Huang, B.; Zhu, N.; Bi, Y.; Ma, X.; Zhan, F.; Wang, L.; Hu, T.; Zhou, H.; Hu, Z.; Zhou, W.; Zhao, L.; Chen, J.; Meng, Y.; Wang, J.; Lin, Y.; Yuan, J.; Xie, Z.; Ma, J.; Liu, W.J.; Wang, D.; Xu, W.; Holmes, E.C.; Gao, G.F.; Wu, G.; Chen, W.; Shi, W.; Tan, W. Genomic characterisation and epidemiology of 2019 novel coronavirus: implications for virus origins and receptor binding. The Lancet 2020, 395, 565-574, https://doi.org/10.1016/S01406736(20)30251-8

7. Cai, J.; Sun, W.; Huang, J.; Gamber, M.; Wu, J.; He, G. Indirect Virus Transmission in Cluster of COVID19 Cases, Wenzhou, China, 2020. Emerging Infectious Disease journal 2020, 26, https://doi.org/10.3201/eid2606.200412. 
8. Christensen, T.; Painter, M. The Politics of SARS - Rational Responses or Ambiguity, Symbols and Chaos? Policy and Society 2004, 23, 18-48, https://doi.org/10.1016/S1449-4035(04)70031-4.

9. Mangiarotti, S.; Peyre, M.; Huc, M. A chaotic model for the epidemic of Ebola virus disease in West Africa (2013-2016). Chaos: An Interdisciplinary Journal of Nonlinear Science 2016, 26, https://doi.org/10.1063/1.4967730.

10. González-Parra, G.; Arenas, A.J.; Chen-Charpentier, B.M. A fractional order epidemic model for the simulation of outbreaks of influenza A(H1N1). Mathematical Methods in the Applied Sciences 2014, 37, 2218-2226, https://doi.org/10.1002/mma.2968.

11. Wan, Y.; Shang, J.; Graham, R.; Baric, R.S.; Li, F. Receptor Recognition by the Novel Coronavirus from Wuhan: an Analysis Based on Decade-Long Structural Studies of SARS Coronavirus. J Virol 2020, 94, e00127-00120, https://doi.org/10.1128/JVI.00127-20.

12. Imai, Y.; Kuba, K.; Ohto-Nakanishi, T.; Penninger, J.M. Angiotensin-Converting Enzyme 2 (ACE2) in Disease Pathogenesis. Circulation Journal 2010, 74, 405-410, https://doi.org/10.1253/circj.CJ-10-0045.

13. Zhu, N.; Zhang, D.; Wang, W.; Li, X.; Yang, B.; Song, J.; Zhao, X.; Huang, B.; Shi, W.; Lu, R.; Niu, P.; Zhan, F.; Ma, X.; Wang, D.; Xu, W.; Wu, G.; Gao, G.F.; Tan, W. A Novel Coronavirus from Patients with Pneumonia in China, 2019. 2020, 382, 727-733, https://doi.org/10.1056/nejmoa2001017.

14. "Daily-Bulletin" (PDF). Directorate of Health Services, Kerala. (Various issues) 2020. https://covid19kerala.info; Maintained by Volunteers at CODD-K Team. Supported by Government College Kasaragod.

15. Chen, N.; Zhou, M.; Dong, X.; Qu, J.; Gong, F.; Han, Y.; Qiu, Y.; Wang, J.; Liu, Y.; Wei, Y.; Xia, J.a.; Yu, T.; Zhang, X.; Zhang, L. Epidemiological and clinical characteristics of 99 cases of 2019 novel coronavirus pneumonia in Wuhan, China: a descriptive study. The Lancet 2020, 395, 507-513, https://doi.org/10.1016/S0140-6736(20)30211-7.

16. Huang, C.; Wang, Y.; Li, X.; Ren, L.; Zhao, J.; Hu, Y.; Zhang, L.; Fan, G.; Xu, J.; Gu, X.; Cheng, Z.; Yu, T.; Xia, J.; Wei, Y.; Wu, W.; Xie, X.; Yin, W.; Li, H.; Liu, M.; Xiao, Y.; Gao, H.; Guo, L.; Xie, J.; Wang, G.; Jiang, R.; Gao, Z.; Jin, Q.; Wang, J.; Cao, B. Clinical features of patients infected with 2019 novel coronavirus in Wuhan, China. The Lancet 2020, 395, 497-506, https://doi.org/10.1016/S01406736(20)30183-5.

17. Chan, J.F.-W.; Yuan, S.; Kok, K.-H.; To, K.K.-W.; Chu, H.; Yang, J.; Xing, F.; Liu, J.; Yip, C.C.-Y.; Poon, R.W.-S.; Tsoi, H.-W.; Lo, S.K.-F.; Chan, K.-H.; Poon, V.K.-M.; Chan, W.-M.; Ip, J.D.; Cai, J.-P.; Cheng, V.C.-C.; Chen, H.; Hui, C.K.-M.; Yuen, K.-Y. A familial cluster of pneumonia associated with the 2019 novel coronavirus indicating person-to-person transmission: a study of a family cluster. The Lancet $\mathbf{2 0 2 0}$, 395, 514-523, https://doi.org/10.1016/S0140-6736(20)30154-9.

18. News Kerala http://www.pinkerala.com/news/keralas-covid-19-death-rate-far-below-the-global-average

19. Gandhi, M.; Yokoe, D.S.; Havlir, D.V. Asymptomatic Transmission, the Achilles' Heel of Current Strategies to Control Covid-19. New England Journal of Medicine 2020, 382, 2158-2160, https://doi.org/10.1056/NEJMe2009758.

20. India Today. Coronavirus curve in Kerala starts to bend: A look at numbers. 2020. https://www.indiatoday.in/india/story/coronavirus-curve-in-kerala-starts-to-flatten-a-look-at-numbers1666479-2020-04-13

21. Oommen, C.K. How the Indian state of Kerala flattened the coronavirus curve. 2020. https://www.theguardian.com/commentisfree/2020/apr/21/kerala-indian-state-flattened-coronavirus-curve

22. Nidheesh M.K. Covid-19: 2020. Big relief for Kerala as 61 recover, active cases drop to 34. https://www.livemint.com/news/india/covid-19-big-relief-for-kerala-as-61-recover-active-cases-drop-to34-11588593927118.html 